Check for updates

The BMJ

rcoombes@bmj.com

Cite this as: BMJ 2020;371:m4971

http://dx.doi.org/10.1136/bmj.m4971

Published: 31 December 2020

\section{Covid-19: Frontline doctors speak out about struggle to maintain care standards}

Rebecca Coombes head of journalism

Frontline doctors have testified to deteriorating conditions in hospitals in London and the south east as the NHS deals with a surge in covid-19 cases.

Speaking to the Independent SAGE group of experts on 30 December, ${ }^{1}$ Jess Potter, a respiratory doctor in east London, told how she and colleagues were afraid of resources running out.

"My greatest fear is having a patient that I cannot provide lifesaving treatment to," she said. "We had one of our largest medical intakes yesterday, the vast majority with coronavirus. What do we do when we run out of resources, and who is going to provide that guidance? It will harm our patients and our staff, because we have a set of values by which we practise, and we will have to reduce the level of care we deliver."

She added, "Back in April I never saw a case where we didn't provide a bed to a patient who needed it in intensive care, and decisions were taken as if in normal times. Now I hear from medics across the country that things are very bad, and the situation is the same as in April, if not worse. We are afraid of what will happen if we don't act now."

Sonia Adesara, a doctor in London, spoke to Independent SAGE after a set of night shifts at her trust and told of a chronic shortage of continuous positive airway pressure (CPAP) capacity.

"In the past few days, despite my hospital significantly increasing intensive and critical care capacity, our intensive care unit has been full, and there is no spare CPAP capacity. Medics are spending shifts trying to closely monitor all of our patients who are on the highest level of oxygen that we can give with a normal mask, assessing who is most unwell and unstable-and then frequently checking on patients who are on CPAP and then swapping people [around].

"It is a very tight situation, and this is not usually how we do medicine in this country."

Adesara described how the emergency department resus unit had become a CPAP ward to accommodate a growing number of patients. She said, "It is increasingly difficult to give non-covid patients optimum care and to keep them safe from covid. Covid cases are spilling out everywhere in the hospital."

She added that, when the trust tried to divert ambulances, they were told that neighbouring hospitals were all full. "Could we have a more formalised divert system covering a larger area, so that north London patients go to south London?” she asked.

The BMA's council chair, Chaand Nagpaul, said, "We are extremely worried that there may not be the capacity in our health service to provide care for everyone who needs it if the infection rates continue to soar."

In April the BMA issued new ethics guidance ${ }^{23}$ stating that, although the decision to deny treatment to a patient who would have received it outside a pandemic would be difficult for doctors, it may become necessary and would be "both lawful and ethical," as long as the appropriate prioritisation policies were followed.

Independent SAGE. indie_SAGE: YouTube live stream. 30 Dec 2020. https://www.youtube.com/watch?v=-klcCUY5vWc.

Mahase E. Covid-19: Patients who are improving could have treatment withdrawn if others could benefit more. BMJ2020;369:m1382. doi: 10.1136/bmj.m1382 pmid: 32241813

3 BMA. Covid-19: ethical issues. Apr 2020 (updated 7 Sep). https://www.bma.org.uk/advice-and-support/covid-19/ethics/covid-19-ethical-issues. 